\title{
ОБЕСПЕЧЕНИЕ ПРОДОВОЛЬСТВЕННОЙ БЕЗОПАСНОСТИ РОССИИ КАК УСЛОВИЕ ПОВЫШЕНИЯ КАЧЕСТВА ЖИЗНИ
}

\author{
М. А. Михаленко \\ Московский гуманитарный университет
}

\begin{abstract}
Аннотация: В статье проанализирована проблема продовольственного обеспечения, как одного из важнейших условий высокого уровня и качества жизни населения. Тема имеет особое значение, является сферой государственных стратегических интересов, требующей особого внимания.

Ключевые слова: продовольственная безопасность; уровень жизни населения; качество жизни населения; безопасность

\section{ENSURING FOOD SECURITY IN RUSSIA AS A CONDITION OF IMPROVING THE QUALITY OF LIFE OF ITS POPULATION}

\author{
M. A. Mikhalenko \\ Moscow University for the Humanities
}

Abstract: The article analyzes the problem of food supply as one of the most important conditions of a high level and quality of life of the population. The topic is of particular importance, it is a sphere of state strategic interests requiring special attention. security

Keywords: food security; standard of living; quality of life of the population;

Современная социально-экономическая ситуация в России, сложившаяся в результате падения уровня жизни населения, высокой дифференциации населения по доходам, сокращения объемов производства отечественной пищевой промышленности и потребления продуктов питания, потенциально опасных для жизни и здоровья людей, обостряет продовольственную безопасность страны. В настоящее время качественное продовольственное обеспечение населения обретает повышенное макроэкономическое значение и становится фактором эффективного роста экономики страны. Вместе с тем несовершенство правовых и организационных механизмов приводит к тому, что в России имеет место проблема экономической доступности продовольствия, а также оборот некачественных и фальсифицированных продуктов питания.

Такую ситуацию усугубляет стремительное падение отечественно- 
го производства пищевой промышленности и устойчивый рост импорта основных видов пищевой продукции. На сегодняшний день темпы собственного производства не отвечают возросшим потребностям населения и не способствуют насыщению рынков отечественной продукцией, что также ставит под угрозу продовольственную и национальную безопасность страны в целом.

В утвержденной Указом Президента Российской Федерации от 30 января 2010 г. № 120 «Доктрине продовольственной безопасности Российской Федерации» (Доктрина продовольственной безопасности ..., 2010) продовольственная безопасность Российской Федерации является одним из главных направлений обеспечения национальной безопасности страны в среднесрочной перспективе, фактором сохранения её государственности и суверенитета, важнейшей составляющей демографической политики, необходимым условием реализации стратегического национального приоритета - повышение качества жизни российских граждан путем гарантирования высоких стандартов жизнеобеспечения.

По официальным статистическим данным, несмотря на рост номинальных доходов населения, отмечается высокий уровень дифференциации населения по среднедушевому уровню этого показателя, что приводит к неэффективному распределению имеющихся на рынке продуктов питания между различными группами населения. Чрезмерная дифференциация доходов и низкий уровень материального благосостояния остаются одними из самых актуальных проблем и вызывают обеспокоенность населения (Шабунова и др., 2015).

Рассмотрим, как это отразилось на основных социальноэкономических индикаторах уровня жизни населения (см. табл. 1). (Российский статистический ежегодник - 2017, Социальное положение и уровень жизни населения России - 2015).

Таблица 1. Основные социально-экономические индикаторы уровня жизни населения

Table 1. Basic social and economic indicators of the living standard of the

\begin{tabular}{|l|l|l|l|l|l|l|l|l|l|l|}
\hline & $\mathbf{1 9 9 5}$ & $\mathbf{2 0 0 0}$ & $\mathbf{2 0 0 5}$ & $\mathbf{2 0 1 0}$ & $\mathbf{2 0 1 1}$ & $\mathbf{2 0 1 2}$ & $\mathbf{2 0 1 3}$ & $\mathbf{2 0 1 4}$ & $\mathbf{2 0 1 5}$ & $\mathbf{2 0 1 6}$ \\
\hline $\begin{array}{l}\text { Среднедушевые } \\
\text { денежные доходы } \\
\text { населения (в месяц), } \\
\text { руб. }\end{array}$ & 515,5 & 2288 & 8112 & 18958 & 20780 & 23221 & 25928 & 27767 & 30225 & 30738 \\
\hline $\begin{array}{l}\text { Реальные } \\
\text { располагаемые } \\
\text { денежные доходы, } \\
\text { в процентах к } \\
\text { предыдушему году }\end{array}$ & 85 & 112 & 112 & 106 & 100 & 105 & 104 & 99 & 96 & 94 \\
\hline
\end{tabular}




\begin{tabular}{|c|c|c|c|c|c|c|c|c|c|c|}
\hline $\begin{array}{l}\text { Величина } \\
\text { прожиточного } \\
\text { минимума (в среднем } \\
\text { на душу населения): } \\
\text { руб. в месяц }\end{array}$ & 264 & 1210 & 3018 & 5688 & 6369 & 6510 & 7306 & 8050 & 9701 & 9828 \\
\hline $\begin{array}{l}\text { в процентах к } \\
\text { предыдущему году }\end{array}$ & 305 & 120 & 119 & 110 & 112 & 102 & 108 & 110 & 121 & 101 \\
\hline $\begin{array}{l}\text { Коэффициент фондов } \\
\text { (коэффициент } \\
\text { дифференциации } \\
\text { доходов), в разах }\end{array}$ & 13,5 & 13,9 & 15,2 & 16,6 & 16,2 & 16,4 & 16,3 & 16,0 & 15,6 & 15,7 \\
\hline $\begin{array}{l}\text { Минимальный размер } \\
\text { оплаты труда (в } \\
\text { среднем за год), руб. }\end{array}$ & 42,5 & 107,8 & 746,7 & 4330 & 4471 & 4611 & 5205 & 5554 & 5965 & 6852 \\
\hline $\begin{array}{l}\text { Численность населения } \\
\text { с денежными доходами } \\
\text { ниже величины } \\
\text { прожиточного } \\
\text { минимума: млн. } \\
\text { человек }\end{array}$ & 36,3 & 41,9 & 25,2 & 17,7 & 17,9 & 15,4 & 15,5 & 16,1 & 19,1 & 19,8 \\
\hline $\begin{array}{l}\text { в процентах от общей } \\
\text { численности населения }\end{array}$ & 24,7 & 28,9 & 17,7 & 12,5 & 12,7 & 10,7 & 10,8 & 11,2 & 13,3 & 13,5 \\
\hline $\begin{array}{l}\text { Дефицит денежного } \\
\text { дохода: млрд. руб. (до } \\
1998 \text { г. - трлн. руб.) }\end{array}$ & 34,8 & 197,8 & 286,9 & 375,0 & 424,1 & 370,5 & 417,9 & 478,7 & 684,9 & 722,3 \\
\hline $\begin{array}{l}\text { в процентах от общего } \\
\text { объема денежных } \\
\text { доходов населения }\end{array}$ & 3,8 & 5,0 & 2,1 & 1,2 & 1,2 & 0,9 & 0,9 & 1,0 & 1,3 & 1,3 \\
\hline
\end{tabular}

Непременным индикатором уровня жизни населения являются расходы на приобретение продуктов питания (там же). В 2016 г. в структуре потребительских расходов доля расходов на покупку продуктов питания составила 32\%, покупательная способность среднедушевых денежных доходов населения снизилась, в т. ч. по всем позициям продовольственных товаров. С 2012 г. по 2016 г. численность населения с денежными доходами ниже величины прожиточного минимума выросла более чем на 4 млн человек. Расчеты показывают, что у значительной части населения России есть серьезные проблемы с экономической доступностью к качественному продовольствию.

В основе многообразия обеспечения продовольственной безопасности страны лежит экономическая доступность продовольствия с высокими потребительскими свойствами, отвечающая критериям качества и принципам здорового питания.

Потребление качественной пищевой продукции влияет на здоровье, увеличение продолжительности жизни и трудоспособности населения, на снижение общей заболеваемости и коэффициента смертности, удовлетворенность жизнью и, как следствие, на повышение качества жизни населения и состояние здоровья нации. Состояние здоровья - один из са- 
мых важных индикаторов благополучия общества в целом (Дробышева, Герасимов, 2004) (см. табл. 2) (Здравоохранение в России, 2015).

Таблица 2. Заболеваемость населения по основным классам болезней Table 2. Disease incidence by basic types of ailments

\begin{tabular}{|c|c|c|c|c|c|c|c|c|c|}
\hline & 1995 & 2000 & 2005 & 2010 & 2011 & 2012 & 2013 & 2014 & 2015 \\
\hline Все болезни & 96322 & 106328 & 105886 & 111428 & 113922 & 113688 & 114721 & 114989 & 113927 \\
\hline $\begin{array}{l}\text { инфекционные } \\
\text { и паразитарные } \\
\text { болезни }\end{array}$ & 5165 & 6448 & 5312 & 4690 & 4626 & 4592 & 4434 & 4504 & 4116 \\
\hline новообразования & 820 & 1226 & 1357 & 1540 & 1586 & 1656 & 1629 & 1693 & 1672 \\
\hline $\begin{array}{l}\text { болезни эндокринной } \\
\text { системы, расстройства } \\
\text { питания, нарушения } \\
\text { обмена веществ и } \\
\text { иммунитета }\end{array}$ & 539 & 1234 & 1361 & 1461 & 1475 & 1519 & 1527 & 1636 & 1953 \\
\hline $\begin{array}{l}\text { болезни крови } \\
\text { и кроветворных } \\
\text { органов }\end{array}$ & 195 & 551 & 647 & 705 & 676 & 675 & 668 & 688 & 692 \\
\hline $\begin{array}{l}\text { болезни нервной } \\
\text { системы и органов } \\
\text { чувств }\end{array}$ & 6778 & 2227 & 2178 & 2345 & 2354 & 2330 & 2364 & 2370 & 2257 \\
\hline $\begin{array}{l}\text { болезни системы } \\
\text { кровообращения }\end{array}$ & 1661 & 2483 & 3278 & 3734 & 3804 & 3814 & 4285 & 4205 & 4563 \\
\hline $\begin{array}{l}\text { болезни органов } \\
\text { дыхания }\end{array}$ & 49733 & 46170 & 41915 & 46281 & 48437 & 47381 & 48568 & 48708 & 49464 \\
\hline $\begin{array}{l}\text { болезни органов } \\
\text { пищеварения }\end{array}$ & 4022 & 4698 & 5034 & 4778 & 4767 & 4982 & 5055 & 5342 & 5163 \\
\hline $\begin{array}{l}\text { болезни мочеполовой } \\
\text { системы }\end{array}$ & 2897 & 5470 & 6560 & 6842 & 7050 & 7101 & 7147 & 7164 & 6793 \\
\hline $\begin{array}{l}\text { осложнения } \\
\text { беременности, родов } \\
\text { и послеродового } \\
\text { периода }\end{array}$ & 1315 & 2085 & 2471 & 2889 & 2816 & 2832 & 2778 & 2801 & 2618 \\
\hline $\begin{array}{l}\text { врожденные } \\
\text { аномалии (пороки } \\
\text { развития) }\end{array}$ & 105 & 214 & 243 & 295 & 303 & 299 & 298 & 307 & 297 \\
\hline
\end{tabular}

За анализируемый период с 1995 по 2015 гг. наблюдается рост общей заболеваемости. При этом количество болезней эндокринной системы, расстройства питания, нарушения обмена веществ и иммунитета, крови и кроветворных органов возросло более чем в 3 раза, врожденных аномалий (пороков развития), новообразований, осложнения беременности, родов и послеродового периода - более чем в 2 раза.

Оборот некачественных и фальсифицированных продуктов питания, имеющий место в России, является причиной развития ряда 
заболеваний населения, влечет за собой необратимые демографические изменения, снижение ожидаемой продолжительности жизни и потери трудоспособности населения.

Результаты экономической деятельности за период с 1990 по 2015 г. свидетельствуют о стремительном падении отечественного производства пищевой промышленности (см. табл. 3) (Промышленость в России, 2016).

Таблица 3. Производство отечественных продовольственных товаров Table 3. Production of domestic foodstuffs

\begin{tabular}{|c|c|c|c|c|c|c|c|c|c|}
\hline & 1990 & 2000 & 2005 & 2010 & 2011 & 2012 & 2013 & 2014 & 2015 \\
\hline $\begin{array}{l}\text { Мясо, включая субпродукты I } \\
\text { категории, тыс. т., в том числе: }\end{array}$ & 6484 & 1194 & 1857 & 3914 & 4239 & 4732 & 5309 & 5957 & 6631 \\
\hline говядина и телятина, тыс. т & 2934 & 389 & 329 & 263 & 229 & 214 & 240 & 224 & - \\
\hline баранина, тыс. т & 176 & 5,2 & 4,5 & 7,2 & 7,3 & 6,0 & 5,7 & 6,1 & - \\
\hline свинина, тыс. т & 1804 & 279 & 337 & 813 & 877 & 1001 & 1300 & 1526 & - \\
\hline $\begin{array}{l}\text { прочие виды мяса и субпродукты } \\
\text { I категории, тыс. т }\end{array}$ & 301 & 40,2 & 45,4 & 93,4 & 102 & 120 & 164 & 220 & - \\
\hline Мясные полуфабрикаты, тыс. т & 1075 & 244 & 987 & 1625 & 1934 & 2254 & 2501 & 2725 & 2911 \\
\hline Колбасные изделия, тыс. т & 2283 & 1052 & 2014 & 2439 & 2486 & 2521 & 2501 & 2476 & 2280 \\
\hline $\begin{array}{l}\text { Товарная пищевая рыбная } \\
\text { продукция (включая консервы } \\
\text { рыбные). млн. т }\end{array}$ & 4,3 & 3,0 & 3,4 & 3,6 & 3,6 & 3,7 & 3,8 & 3,7 & 3,8 \\
\hline $\begin{array}{l}\text { Цельномолочная продукция (в } \\
\text { пересчете на молоко), млн. т }\end{array}$ & 20,8 & 6,2 & 9,7 & 10,9 & 10,7 & 11,3 & 11,5 & 11,5 & - \\
\hline Масло сливочное, тыс.т & 833 & 267 & 254 & 212 & 219 & 216 & 227 & 253 & 258 \\
\hline $\begin{array}{l}\text { Сыры жирные (включая брынзу), } \\
\text { тыс. т }\end{array}$ & 458 & 221 & 378 & 437 & 432 & 451 & 435 & 499 & - \\
\hline Мука, млн. т & 20,7 & 12,1 & 10,4 & 9,9 & 10,0 & 10,2 & 9,9 & 9,8 & 9,9 \\
\hline Крупа, тыс. т & 2854 & 932 & 972 & 1270 & 1177 & 1412 & 1353 & 1350 & 1430 \\
\hline $\begin{array}{l}\text { Хлеб и хлебобулочные изделия, } \\
\text { млн. т }\end{array}$ & 18,2 & 9,0 & 8,0 & 7,3 & 7,1 & 7,0 & 7,0 & 6,8 & 6,8 \\
\hline Сахар, тыс. т, & 3758 & 6077 & 5600 & 4751 & 7124 & 5322 & 4959 & 5249 & 5743 \\
\hline Макаронные изделия, тыс. т & 1077 & 704 & 993 & 1063 & 1035 & 994 & 915 & 995 & 1152 \\
\hline
\end{tabular}


Как видно из таблицы № 3 за анализируемый период произошли существенные изменения в производстве основных видов пищевой продукции. Так, производство говядины сократилось более чем в 12 раз, баранины в 30 раз, молока в 2 раза, масла сливочного в 3,6 раза, муки в 2 раза, хлеба и хлебобулочных изделий в 2,6 раза. Следует отметить, что основной спад производства произошел в период реформирования России с 1992 по 2000 гг. при этом промежуточная динамика за анализируемый период также имеет тенденцию к снижению.

Основой обеспечения продовольственной безопасности населения может служить не только развитие отечественной пищевой и фармацевтической промышленности, но и продовольственной системы страны в целом. Учитывая рекомендации Министерства здравоохранения и социального развития Российской Федерации по рациональным нормам потребления пищевых продуктов, отвечающим современным требованиям здоровогопитания,проследим изменениеобъёмовосновных видов пищевой продукции, произведённых в 1990 и 2014 гг., с нормами потребления на душу населения (Рекомендации по рациональным ... , Электр. ресурс) (см. табл. 4).

Таблица 4. Соотношение годового производства и годовой потребности в основных продуктах питания в среднем по России (кг. на душу населения в год) Table 4. The correlation of annual production and annual need for basic foodstuffs on average in Russia ( $\mathrm{kg}$ per head per annum)

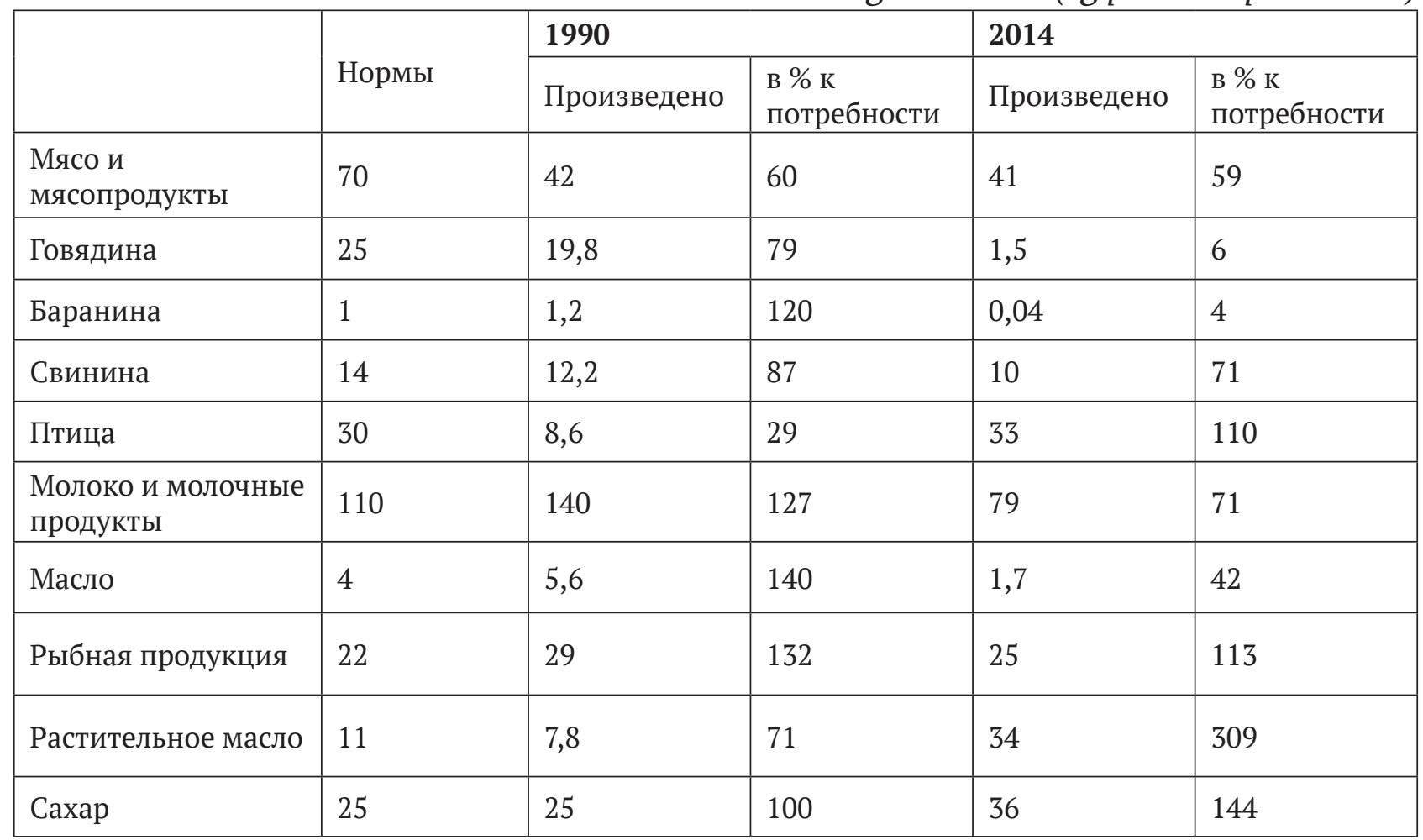


Соотношение годового производства и годовой потребности в основных продуктах питания в среднем по России свидетельствует о том, что продовольственная независимость по состоянию на 1990 г. обеспечивалась в основном по всем видам пищевой продукции. Вместе с тем за последующие десятилетия положение с обеспечением населения отечественной продукцией кардинально изменилось. К 2014 г. производство говядины на душу населения составило - 6\% отпотребности, баранины $-4 \%$, масла $-42 \%$, молока $-71 \%$. В то же время пороговые значения обеспечения страны собственными продовольственными ресурсами составляют по мясу $-85 \%$, молоку и молокопродуктам $-90 \%$.

Таким образом, производство основных видов пищевых продуктов осуществляется в объемах меньших, чем установленные пороговые значения их удельного веса в товарных ресурсах внутреннего рынка (без учета переходящих запасов), что обостряет продовольственную безопасность страны.

Произошедшее за последние 25 лет падение отечественного производства продовольственных товаров привело к массовому наплыву более дешевых, но зачастую, менее качественных импортных товаров. По даннымРосстата,в 1990г.импортпродовольствия исельскохозяйственного сырья составлял 9,6 млрд. долл. США, в 2016 г. он увеличился более чем в 2,5 раза и составил 24,6 млрд. долл. США. За эти годы импорт мяса возрос в 4,5 раза, молока и сливок в 4,6 раза, сливочного масла в 5,2 раза, картофеля в 3,1 раза, рыбы в 18,9 раза. Импорт основных видов пищевой продукции сопровождается сокращением посевных площадей и поголовья скота. На сегодняшний день доля импортных продуктов питания в рационе населения составляет около $40 \%$ от общего объёма их потребления.

Следует отметить, что конкурентные преимущества импортных товаров пищевой промышленности перед отечественными продуктами питания формируются за счет различных мер государственной поддержки производства пищевых продуктов в зарубежных странах.

На фоне стремительного падения отечественного производства основных видов продовольственных товаров в период с 1995 г. по 2016 г. число действующих предприятий пищевой промышленности возросло более чем в 3 раза. Вместе с тем результаты их деятельности привели к низкой доходности и увеличению задолженности. Суммарная задолженность по обязательствам предприятий пищевой промышленности, по официальным данным статистики, увеличилась более чем в 4,8 раза. Удельный вес убыточных организаций в общем числе организаций достиг 24,7\%. Рентабельность снизилась с 16,3 до 9,9\%, которая значительно ниже минимально допустимого уровня.

За эти годы степень износа основных фондов пищевой про- 
мышленности, по данным Росстата (Промышленность в России, 2016), достигла с 21 до 48,6\%, при этом удельный вес полностью изношенных основных фондов в 2015 г. составил 15,9\%.

Крайне остро стоит вопрос с инновационной активностью предприятий и разработкой новых технологий в пищевой промышленности. Уровень технологического развития отечественной производственной базы значительно отстает от развитых стран. Таким образом, продовольственное обеспечение населения доступными и качественными продуктами питания приобретает особое значение, является фактором эффективного роста экономики страны и важнейшим условием повышения уровня и качества жизни населения.

Современная ситуация требует более активного использования всего набора инструментов регулирования экономики, имеющегося в распоряжении государства. При этом необходимо научное обоснование концептуальных основ формирования политики продовольственного обеспечения и механизмов ее реализации.

\section{СПИСОК ЛИТЕРАТУРЫ}

ДоктринапродовольственнойбезопасностиРоссийскойФедерации. Утверждена Указом Президента Российской Федерации от 30 января 2010 г. № 120 [Электронный ресурс] // Президент РФ (официальный сайт). URL: http://www.kremlin.ru/events/president/news/6752 (дата обращения: 24.06.2017).

Дробышева, В. В., Герасимов, Б. И. (2004) Интегральная оценка качества жизни населения региона. Тамбов: Издательство Тамбовского государственного технического университета. 108 с.

Рекомендации по рациональным нормам потребления пищевых продуктов, отвечающим современным требованиям здорового питания. Утверждены приказом Министерства здравоохранения и социального развития Российской Федерации (Минздравсоцразвития) от 2 августа 2010 г. № 593н. [Электронный ресурс] // Официальный портал Министерства здравоохранения Российской Федерации. URL: URL: https:/www.rosminzdrav.ru/news/2016/08/26/3128-prikazom-minzdrava-rossii-utverzhdenyrekomendatsii-po-ratsionalnym-normam-potrebleniya-pischevyh-produktov (дата обращения: 24.06.2017).

Российский статистический ежегодник. [Электронный ресурс]// Официальный портал Федеральной службы государственной статистики// URL:http://www.gks.ru/free_doc/doc_2017/rusfig/rus17.rar (дата обращения: 24.06.2017).

Социальное положение и уровень жизни населения России. [Электронный ресурс]// Росстат.URL:http://www.gks.ru/free_doc/doc_2015/ 
soc-pol.rar (дата обращения: 24.06.2017).

Здравоохранение в России. [Электронный ресурс] // Росстат. URL: http://www.gks.ru/free_doc/doc_2015/zdravo.rar (дата обращения: 24.06.2017).

Промышленность в России. [Электронный ресурс] // Росстат. URL: http://www.gks.ru/free_doc/doc_2016/prom.rar (дата обращения: 24.06.2017).

Шабунова, А. А., Морев, М. В., Россошанский, А. И., Белехова, Г. В. (2015) Уровень жизни и социальная реальность: мониторинг перемен. Вологда : ИСЭРТ РАН. 122 с.

Дата поступления: 09.12.2017 2.

Михаленко Максим Александрович - аспирант кафедры экономических и финансовых дисциплин Московского гуманитарного университета. Адрес: 111395, Россия, г. Москва, ул. Юности, д. 5. Тел.: +7 (499) 374-73-61. Эл. адрес: mvft@mail.ru. Научный руководитель - д-р экон. н., проф. Н. А. Смирнова.

Mikhalenko Maksim Aleksandrovich, Post-Graduate Student, Department of Economic and Financial Disciplines, Moscow University for the Humanities. Postal address: 5, Yunosti St., Moscow, Russian Federation 111395. E-mail: mvft@mail.ru. Scientific Adviser - N. A. Smirnova, Doctor of Economics, Professor.

\section{Для циитирования:}

Михаленко М. А. Обеспечение продовольственной безопасности России как условие повышения качества жизни населения [Электронный ресурс] // Научные труды Московского гуманитарного университета. 2017, № 3. URL: http://journals.mosgu. ru/trudy/article/view/506 (дата обращения: дд.мм.гг.). DOI: 10.17805/trudy.2017.3.12 